\title{
ARTE E GÊNERO: A PRODUÇÃO ARTÍSTICA DE MULHERES NA FORMAÇÃO DE PROFESSORES E PROFESSORAS DE ARTES VISUAIS
}

\author{
Catarina Siqueira Figueredo ${ }^{1}$
}

\section{INTRODUÇÃO}

Este relato refere-se a uma pesquisa realizada no segundo semestre de 2015, a fim de cumprir a disciplina de Trabalho de Conclusão de Curso, do curso de Artes Visuais da Universidade do Extremo Sul Catarinense. O ponto de partida desta pesquisa encontra-se e em inquietações pessoais da acadêmica-pesquisadora e em suas vivencias do cotidiano. Sendo assim a pesquisa inicia-se com o seguinte problema "Os alunos de Artes Visuais Licenciatura, da UNESC, se apropriam da arte produzida por mulheres e isso tem reflexo na sua formação?"

Neste sentido esta pesquisa se caracteriza por ser de natureza básica e com uma abordagem qualitativa. Quanto aos procedimentos técnicos, esta investigação se constitui como uma pesquisa bibliográfica e de campo. Deste modo a pesquisa bibliográfica abrange os seguintes temas: o feminismo, os estudos de gênero, as relações entre a arte e o movimento feminista e as relações entre gênero e educação. Na pesquisa de campo foram utilizados os seguintes instrumentos de pesquisa: o questionário e a entrevista semiestruturada. As entrevistas semiestruturadas foram realizadas com nove professores e professoras do Curso de Arte Visuais da UNESC e os questionários foram aplicados com alunos da sexta e oitava fases do segundo semestre de 2015, do Curso de Arte Visuais Licenciatura da UNESC. Sendo assim um total de 23 acadêmicos entrevistados.

A investigação em questão procura compreender como a arte produzida por mulheres foi ou não abordada nas aulas do curso de Artes Visuais Licenciatura, da UNESC e como os acadêmicos das duas últimas fases do segundo semestre de 2015 se apropriaram ou não destas abordagens. Procura-se ainda saber, se abordadas, de que forma e isso acontece e como se dá a recepção dos acadêmicos e das acadêmicas. Durante a pesquisa, também, pode-se estabelecer

\footnotetext{
${ }^{1}$ Universidade do Extremo Sul Catarinense - catarinasfigueredo@hotmail.com
} 
relações entre a pesquisa bibliográfica e a pesquisa de campo, através das falas e respostas dos participantes.

\section{O FEMINISMO E OS ESTUDOS DE GÊNERO}

O primeiro passo da pesquisa bibliográfica abrange o feminismo e os estudos de gênero. Percebe-se assim que ainda hoje há a presença de diversos estereótipos relacionados ao gênero feminino e masculino. Além destes estereótipos, há ainda a desigualdade presente em diversos setores da vida social, inclusive no campo das artes. Durante muito tempo, a história da arte enfatizou "um olhar masculino, branco, europeu e heteronormativo." (LOPONTE, 2005, p. 246). Com essa predominância da produção de arte masculina, por muito tempo a produção de artistas mulheres se viu oprimida e desvalorizada. Porém o que percebemos, ao buscar por imagens de obras de arte ao longo da história, é que as imagens de mulheres foram temas presentes e constantes nas produções masculinas. Esta realidade reafirma a "pedagogia que naturaliza e legitima o corpo feminino como objeto de contemplação." (LOPONTE, 2008, p. 152).

É a partir da luta contra esta invisibilidade, que surge, nos anos 70, a ideia de "resgatar a importância da mulher na História da Arte." (DIAS, 2005, p. 278). Este que é um dos primeiros objetivos do movimento feminista que ganhou força na década de 1960 nos Estados Unidos, juntamente com a luta pelos direitos civis. Sendo assim, foi na década de 1960 que o termo gênero passou a ser utilizado em estudos acadêmicos e nos discursos feministas, destacando que as diferenças são sociais e culturais, e não naturais.

Simone de Beauvoir (1980) afirma que "Não se nasce mulher, torna-se mulher." De forma geral, dentro das sociedades ocidentais, é esperado que cada gênero assuma suas características pré-determinadas, levando em consideração o seu sexo biológico. "Por exemplo, nascer mulher significa ter a capacidade reprodutiva para ser mãe (o sexo biológico). No entanto, é a cultura que determina os muitos significados que a maternidade assume." (SANTA CATARINA, 2014 p. 5859). Quando idealizamos que todas as mulheres nascem com um suposto instinto maternal, estamos pré-determinando o comportamento das mulheres e, ao enquadrá-las vinculadas a um suposto "instinto", acabamos por negar o direito da 
livre escolha às mulheres (BADINTER, 1985). Neste sentido Scott $(1989$, p.3) afirma que:

Gênero é compreendido como um meio de classificar fenômenos, um sistema de distinções socialmente acordado mais do que uma descrição objetiva de traços inerentes. Além disso, as classificações sugerem uma relação entre categorias que permite distinções ou agrupamentos separados.

Nesta afirmação Scott aponta o gênero a partir do sexo biológico, feminino e masculino. Porém estas categorias ficam mais evidentes a partir das relações sociais, culturais e as relações historicamente determinadas. O que nos faz repensar os estereótipos vinculados ao feminino e ao masculino. Algo que nos faz refletir e reanalisar estas categorias e características é a teoria queer, que vem a afirma que o gênero é performativo (BUTLER, 2003).

\section{A ARTE E O MOVIMENTO FEMINISTA}

Com os estudos de gênero e o movimento feminista que surge aproximadamente na década de 1960, algumas reverberações são causadas nos mais diversos setores da vida social, deste modo no campo das artes também surgem novos olhares e reflexões. Sobre essas reverberações podemos apontar que "o movimento feminista na arte vem então para desconstruir a premissa de mulher objeto de desejo. De musas inspiradoras para o olhar do artista, passamos a ser o olho e a mão que cria." (TRIZOLLI, 2008, p.1498). As mulheres passam a assumir a identidade de artista, adotam suas próprias temáticas, saem das telas e deixam de serem as esculturas, para assumir a posição de artista.

A princípio as artistas mulheres passam a negar as linguagens tradicionais como, por exemplo, a pintura e a escultura, e assim passam a aderir às linguagens contemporâneas, vídeo art, instalações, performance entre outras. Durante o movimento uma das principais iniciativas era realizar "um exercício de recuperação histórica." (ARCHER, 2001, p. 92), o que podemos observar claramente em algumas obras de artistas como Judy Chicago, mais especificamente na obra "O Jantar" de 1974-79. O movimento feminista na arte surge com diversas problematizações e reinvindicações, assim como nos outros setores da vida social. Passaram pelo movimento diversas questões reflexivas como, por exemplo, as que são apontadas até hoje pelas artistas do grupo Guerrilla Girls e pelas autoras 
Coutinho e Loponte (2015, p.182): "Por que da desvalorização das mulheres artistas no mercado?", "Por que a porcentagem de mulheres que ocupa galerias e museus é inferior a 10\%?", "As mulheres têm que estar nuas para entrar nos museus?".

É relevante ressaltar outras artistas mulheres e artistas homens, que em seus trabalhos abordam questões ligadas ao movimento feminista e problematizam também questões de gênero. Uma destas artistas é Barbara Kruger, que em sua obra Your comfort is my silence (Seu conforto é o meu silêncio) de 1981, apresenta um homem, com sua identidade velada por um chapéu, no qual com seu gesto pede silêncio a quem observa. A obra em questão é composta por fotografia e colagem, a mesma se difere das obras citadas até então, sendo assim necessário destacar que o movimento feminista na arte não causou uma influencia tão grande as características das obras, como influenciou o conceito aderido às elas. Esse conceitualismo aderido às obras foi marcado pelo teor de denúncia, inconformismo e revolta.

Passado as primeiras décadas do surgimento do movimento feminista (1960/70), as produções artísticas de mulheres passam a ressignificar materiais ditos femininos.

Algumas artistas contemporâneas, principalmente a partir dos anos 90,
surpreendem cada vez mais ao romperem com padrões chamados
"femininos", reciclando e reinventando acervos materiais e simbólicos
constituintes do universo feminino há muito tempo (LOPONTE, 2008, p.
150).

Bordados, pinturas, entre a ressignificação de outros materiais ditos "femininos" voltam a serem produzidos, porém temas abordados passam a problematizar questões levantadas pelo movimento. Neste sentido é importante falar da artista Joana Vasconcelos, que em sua escultura intitulada Marilyn, de 2009, a artista apropria-se de um grande número de panelas e tampas para formar outro objeto dito "feminino" um par de sapatos de salto alto.

Outra artista que trago para conversar com questões vistas até então é a artista Frida Kahlo. Em sua obra Autorretrato com Cabelo Curto, de 1940, a mesma aparece com os cabelos cortados e vestida com um terno, o qual seu corpo cada por perder sua identidade. Na parte superior da pintura há uma frase a qual diz: "Olha, se te amei foi pelo teu cabelo, agora que estás careca, já não te amo." Segundo Ferreira e Rivera (2008, p.240), "devido a essa dimensão que é dada aos cabelos na tela, podemos dizer que os cabelos são tomados como significantes provisórios da 
sexualidade feminina." Ao analisarmos a obra e a história de Kahlo, podemos voltar as afirmações de Judith Butler (2003), onde ela afirma que o gênero é performativo, pois é resultado de normas sociais que regulam os sujeitos, que são divididos e hierarquizados.

Pensado acerca dessa "performatividade" do gênero apontada por Butler, pode-se ressaltar a produção artística de Cindy Sherman. Em seus trabalhos, podese observar um posicionamento social, no qual a identidade e os papéis sociais são questionados. Estas questões podem ser observadas na obra Sem título \#198, de 1989, a qual faz parte de uma série de obras em que a artista permite-se transformar nas mais diversas identidades. Segundo Archer (2001, p.194), "o desejo de Sherman não era tanto se transformar nesses personagens, mas apagar sua própria personalidade, tornando-se neutra [...]". Muito mais do que ressaltar as mulheres artistas na história é importante refletir sobre o que as tornou "invisíveis". Como afirma Scott (1989, p. 163):

Se você usa o gênero como uma ferramenta crítica expondo não só o fato da presença das mulheres na história, mas as razões para sua invisibilidade ou marginalização da política e da vida pública, então você está avançando na 'causa' da emancipação das mulheres.

Pensando nesta politica de igualdade, logo se pode pensar em como colocá-la em prática nas escolas. As escolas e as universidades são os lugares institucionalizados para que essa politica de igualdade aconteça e prevaleça. Mais do que apenas ressaltar e trazer a tona o passado, é necessário escrever um novo futuro com pessoas criticas e conscientes.

\section{GÊNERO E EDUCAÇÃO}

Antes de imergir no universo da educação e sua relação com gênero, é relevante refletir sobre "o que é arte?". Através da ideia assegurada por Coli (2006, p. 08), arte "são certas manifestações da atividade humana diante das quais nosso sentimento é admirativo, isto é: nossa cultura possui uma noção que denomina solidamente algumas de suas atividades e as privilegia." Este mesmo autor ainda afirma que refletir sobre a arte se tornou ainda mais complexo na contemporaneidade. Como já ressaltado nas décadas de 1960 e 1970 a arte começa a permear novos caminhos e contextos o que ampliou ainda mais a sua 
total compreensão. A arte caminha para além da preocupação estética, sendo assim artistas trazem para seus trabalhos questões do cotidiano, questões pessoais, entre outras e para isso as mais diversas linguagens da arte são utilizadas.

A arte faz parte do currículo escolar e junto dela os mais diversos contextos adentram os muros das escolas. Como pode ser visto até então gênero e arte são assuntos que conversam e se entrelaçam, e por consequência ambos participam da rotina escolar, de maneira explícita ou inexplícita.

Para falar sobre gênero e educação, é importante ressaltar a presença do termo gênero nos documentos norteadores para a educação e a relação entre a disciplina de arte e as questões do cotidiano. A presença deste termo se encontra em documentos como, por exemplo, os Parâmetros Curriculares Nacionais (PCN), especificamente o referente aos Temas Transversais, no Plano Nacional de Educação (PNE) e na Proposta Curricular de Santa Catarina (2014). Este último documento citado aponta que em relação a presença do termo gênero no currículo escolar a "necessidade de um Educação Básica que reconheça e assuma a diversidade como um princípio formativo e fundante do currículo escolar." (SANTA CATARINA, 2014, p.54).

Neste sentindo discussões e problematizações a cerca deste tema em especifico nas licenciaturas é de suma importante para que se hajam professores habilitados a abordarem estes temas em aulas da educação básica. Esta pesquisa vem de encontro com que está disposto nos documentos norteadores para a educação e busca investigar se os alunos de Artes Visuais Licenciatura (UNESC) durante o curso se ou não apropriam da arte produzida pelas mulheres e isso tem reflexo na sua formação. Para esta pesquisa, como citado anteriormente, os instrumentos técnicos utilizados foram o questionário e a entrevista semiestruturada.

\section{AS PERCEPÇÕES E OS OLHARES DOS ACADÊMICOS E DAS ACADÊMICAS}

A princípio as percepções e os olhares dos acadêmicos e das acadêmicas do curso mostram que $83 \%$ destes entrevistados compreendem que a diversidade de gênero é um dos assuntos a serem debatidos e compreendidos no ambiente escolar. A mesma porcentagem afirma também saber do que se trata os estudos de gênero e dentre os 23 acadêmicos entrevistados, 21 consideram importante que o curso de Artes Visuais aborde discussões sobre arte e gênero. 
Quando os acadêmicos são questionados por que consideram importante a inserção destas discussões no curso, alguns aspectos são relevados, sendo estes: poucas (pessoas) ainda sabem o que o termo gênero realmente significa, sendo assim necessário esclarecer dúvidas, anseios e preconceitos; este é um tema atual, presente em nossa sociedade contemporânea e em diversas produções artísticas; há dúvidas, entre os acadêmicos, sobre como abordar este tema em sala de aula, destacando a potência na disciplina de artes para adotar este tema; e por fim os acadêmicos entrevistados destacam que é necessário ampliar seus repertórios.

Outra questão que respondida pelos estudantes é referente à maneira como a produção de arte de mulheres é abordada nas disciplinas do curso. De modo geral, os estudantes reconhecem que as artistas mulheres ganham visibilidade na Arte Contemporânea e que este ponto não é exclusivo apenas do campo das artes e sim de todos os espaços da vida social, como cita um acadêmico entrevistado: "Acredito que as artistas femininas tiveram mais espaço nos dias de hoje, na contemporaneidade, pois hoje a mulher tem mais liberdade." Nesta mesma questão um outro acadêmico mostra que a abordagem da produção de mulheres nas disciplinas também é consequência dessa maior aparição da arte de mulheres na contemporaneidade e este afirma que: "Por se tratarem de produções contemporâneas as abordagens são bem diversas. Desde a exacerbação do feminino nas produções até a normalização deste gênero nas propostas artísticas."

\section{AS PERCEPÇÕES E OS OLHARES DOS PROFESSORES E DAS PROFESSORAS}

Sobre as percepções e os olhares dos professores e das professoras entrevistados é importante destacar inicialmente que todos os professores afirmam abordar a produção de mulheres artistas. Porém, dependendo da disciplina isso se torna mais fácil ou mais difícil, tudo isso em decorrência ao ponto anteriormente destacado pelos acadêmicos: a presença mais explicita da mulher artista na contemporaneidade. Referente a essa questão, um professor entrevistado afirma: "Elas estão sempre às margens, são as musas, são as modelos, são as pessoas que escrevem, as que influenciam, mas dentro dessa história que é eurocentrista, judaico-cristã é o homem que prevalece até ali no modernismo." 
Seguindo a pesquisa, em relação à abordagem ou não das questões de gênero nas suas disciplinas do curso em que os professores entrevistados lecionam, três dos nove entrevistados afirmam que não abordam estas questões. Os outros seis professores afirmaram que já abordaram estas questões, porém destacam que o tema não é abordado na perspectiva do currículo e o mesmo surge conforme os artistas abordados. Quando os docentes são questionados sobre qual é a sua opinião, sobre a presença do termo gênero nos documentos e a inserção deste tema nas aulas, todos eles acreditam que este deve ser sim um tema presente nas escolas. Porém é necessária uma compreensão maior acerca do tema, para que não aconteça equívocos. Os docentes destacam também que o tema não deve estar encaixado no currículo, como conteúdo, mas sim como uma discussão paralela às aulas.

Durante as entrevistas os professores também são questionados como entendem a relação entre arte e gênero. Dentre as respostas alguns pontos são ressaltados, o primeiro é de que arte e gênero são duas coisas distintas. Sobre isso um professor afirma que "as questões de gênero, ou as ideologias de gênero, ou os problemas de gênero, são melhores apresentados a partir de um olhar ou de uma linguagem (das diversas linguagens) da arte." O segundo ponto de destaque é a relação entre a arte e a vida, onde outro docente aponta que "a vida está muito impregnada pela arte e a arte está muito impregnada pela vida.". O terceiro e último ponto mostra que na arte contemporânea, estas questões acabam por ganharem maior visibilidade, porém a certa dificuldade de compreender o significado do termo, como a firma um entrevistado:

"Partindo já da nomenclatura que se dá, porque a gente vê que tem
problemas de gênero e será que isso é um problema? Tem ideologia de
gênero e será que isso é uma ideologia? Tem questões de gênero e quais
são estas questões? E a palavra por si só, gênero, porque ela pode ser
confundida com gênero literários, com gênero da questão do feminino ou
masculino, então fica uma coisa muito ampla."

\section{CONSIDERAÇÕES FINAIS}

Percebe-se que há um interesse e uma preocupação com relação ao tema tanto por parte dos professores, que durante a entrevista se dispuseram a compartilhar suas opiniões e conhecimentos, quanto por parte dos alunos que, por meio do questionário, compartilharam suas preocupações e interesses. 
Sendo assim essa investigação nos mostra que a maioria dos acadêmicos compreende do que se tratam os estudos de gênero e também afirmam que este é um dos temas propícios a serem discutidos no ambiente escolar. Estes estudantes entrevistados também ressaltam que há a necessidade e interesse por boa parte deles em se discutir este assunto nas diversas disciplinas do curso de Artes Visuais. O teor político das obras, os conceitos e a relevância no cenário artístico atual são destacados pelos professores e acadêmicos, que ressaltam a presença mais ativa das mulheres na contemporaneidade. Deste modo os professores abordam a produção artística de mulheres, porém a produção de mulheres ganha uma maior visibilidade e reconhecimento na contemporaneidade e como forme a disciplina há certa escasses de materiais e informação sobre estas mulheres artistas. Ainda sobre a abordagem destas produção artisticas os professores afirmam que, não há uma preocupação com o gênero e sim com a qualidade do trabalho e o conteúdo e ainda.

A pesquisa mostra que há a necessidade de um olhar mais sensível para as produções artística de mulheres, sendo estas sujeitos constituintes e ativos de nossa sociedade. Mais do que inserir a produção artística de mulheres, é preciso mostrar a trajetória percorrida pelas mulheres. É preciso continuar dando voz às mulheres, contemplar as conquistas do movimento feminista e continuar assumindo os espaços nos quais as mulheres ainda não estão presentes.

\section{REFERÊNCIAS}

ARCHER, Michael. Arte contemporânea: uma história concisa. São Paulo: Martins Fontes, 2001. $263 \mathrm{p}$.

BADINTER, Elisabeth. Um amor conquistado: o mito do amor materno. 2. Ed. Rio de Janeiro: Nova Fronteira, 1985.

BEAUVOIR, Simone de. O segundo sexo: a experiência vivida. 6. ed. Rio de Janeiro: Nova Fronteira, 1980.

BUTLER, Judith. Problemas de gênero: feminismo e subversão da identidade. Rio de Janeiro: Editora Civilização. Brasileira, 2003.

COLI, Jorge; Lars Erik Gustav Unonius. O que é arte. 11 ed. São Paulo: Ed. Brasiliense, 2006. $131 \mathrm{p}$. 
COUTINHO, Andréa Senra; LOPONTE, Luciana Gruppelli. Artes Visuais e Feminismos: Implicações pedagógicas. Revista Estudos Feministas, Florianópolis, v. 1, n. 23, p.181-190, jan./abr. 2015.

DIAS, Belidson. Entre Arte/Educação multicultura, cultura visual e teoria queer. In: BARBOSA, Ana Mae. Arte/educação contemporânea: consonâncias internacionais. São Paulo: Cortez, 2005. Cap. 7. p. 277-291.

FERREIRA, Renata Wirthmann G.; RIVERA, Tania. Alternância e desejo na feminilidade e na obra de Frida Kahlo. Psicol. USP [online]. 2008, v.19, n.2, p. 235257.

LOPONTE, Luciana Gruppelli. Gênero, Educação e Docência nas Artes Visuais. Educação e Realidade, Porto Alegre, v. 2, n. 30, p.243-259, jul/dez 2005.

LOPONTE, Luciana Gruppelli. Pedagogias visuais do feminino: arte, imagens e docência. Currículo Sem Fronteiras, Porto Alegre, v. 8, n. 2, p.148-164, jul/dez 2008.

SANTA CATARINA, Governo do Estado de. Proposta Curricular de Santa Catarina: Formação integral na educação básica. 2014. Disponível em: <http://www.propostacurricular.sed.sc.gov.br/site/Proposta_Curricular_final.pdf>. Acesso em: 13 set. 2015.

SCOTT, Joan Wallach. Gênero: uma categoria útil para análise histórica. In.: Gender: a useful category of historical analyses. Gender and the politics of history. New York, Columbia University Press. 1989. p. 42 Disponível em: $<$ http://disciplinas.stoa.usp.br/pluginfile.php/185058/mod_resource/content/2/G>.

TRIZOLI, Talita. O Feminismo e a Arte Contemporânea - Considerações. In: ENCONTRO DA ASSOCIAÇÃO NACIONAL DE PESQUISADORES EM ARTES PLÁSTICAS, 17, 2008. Florianópolis. Anais Eletrônicos... 2008. p.1495 - 1505. Disponível em: <http://feminismo.org.br/web/wpcontent/uploads/2014/09/Feminismo-e-arte-contempor\%C3\%A2nea_TalitaTrizoli.pdf>. 